\title{
Hearing loss and quality of life in survivors of paediatric CNS tumours and other cancers
}

Annette Weiss ${ }^{1,2} \cdot$, Grit Sommer $^{1} \cdot$ Christina Schindera $^{1,3} \cdot$, Laura Wengenroth ${ }^{4} \cdot$ Axel Karow $^{3} \cdot$ Manuel Diezi ${ }^{5}$, Gisela Michel ${ }^{6}$, Claudia E. Kuehni ${ }^{1,3} \cdot$ for the Swiss Paediatric Oncology Group (SPOG)

1 Swiss Childhood Cancer Registry, Institute of Social and Preventive Medicine, University of Bern, Mittelstrasse 43, 3012 Bern, Switzerland

2 Department for Epidemiology and Preventive Medicine/Medicine Sociology, University of Regensburg, Franz-Josef-Strauss-Allee 11, 93053 Regensburg, Germany

3 Division of Pediatric Hematology/Oncology, Department of Pediatrics, Inselspital, Bern University Hospital, University of Bern, Freiburgerstrasse 15, 3010 Bern, Switzerland

4 Institute and Outpatient Clinic for Occupational, Social and Environmental Medicine, University Hospital of Munich (LMU), 80336 Munich, Germany

5 Paediatric Haemato-Oncology Unit, Department of Paediatrics, University Hospital Lausanne (CHUV), Rue du Bugnon 46, 1011 Lausanne, Switzerland

6 Department of Health Sciences and Health Policy, University of Lucerne, Frohburgstrasse 3, 6002 Lucerne, Switzerland

Corresponding author: Claudia E. Kuehni, claudia.kuehni@ispm.unibe.ch

\begin{abstract}
Hearing loss, a complication of cancer treatment, may reduce health-related quality of life (HRQoL), especially in childhood cancer survivors of central nervous system (CNS) tumours who often have multiple late effects. We examined the effect of hearing loss on HRQoL in young survivors of CNS and other childhood cancers.
\end{abstract}

Methods: Within the Swiss Childhood Cancer Survivor Study, we sent questionnaires about hearing loss and HRQoL (KIDSCREEN-27) to parents of survivors aged 8-15 years. We stratified the effect of hearing loss on HRQoL by cancer diagnosis, using multivariable logistic regression and adjusting for sociodemographic and clinical factors.

Results: Hearing loss was associated with impaired physical well-being [unadjusted estimated differences -4.6 (CI -9.2; -0.1); adjusted -4.0 (CI -7.6; -0.3)] and peers \& social support [unadjusted 6.7 (CI -13.0; -0.3); adjusted -5.0 (CI -10.5; 0.9)] scores in survivors of CNS tumours $(\mathrm{n}=123)$, but not in children diagnosed with other tumours (all $\mathrm{p}$-values $>0.20, \mathrm{n}=577$ ).

Conclusion: Clinicians should be alert to signs of reduced physical well-being and impaired relationships with peers. Especially survivors of CNS tumours may benefit most from strict audiological monitoring and timely intervention to mitigate secondary consequences of hearing loss on HRQoL.

\section{Introduction}

Hearing loss, especially in the high frequencies, is an adverse event of childhood cancer treatment, particularly after platinum chemotherapy or cranial radiation $\geq 30$ Gray [1].
It is often irreversible and can be uni- or bilateral [1]. Hearing impaired children in the general population have lower health-related quality of life (HRQoL) in domains of school activities and social interactions, which are important for learning $[2,3]$. The only study on hearing loss and HRQoL in young childhood 
cancer survivors is published more than 10 years ago [4], while cancer treatments constantly change. The study focused on patients diagnosed with neuroblastoma (19891995) without factoring in other comorbidities [4]. While hearing loss can pose difficulties for any child, survivors treated for central nervous system (CNS) tumours may suffer more from hearing loss since they often have multiple late effects which may reduce their social and educational skills [5]. Recently, oncologists have become more aware of ototoxicity [6-8]. Survivors should be carefully monitored for audiological problems and offered timely and targeted interventions to help them cope with hearing loss [9]. Audiological monitoring has not yet been fully implemented for survivors in follow-up care in Switzerland [8] and there is, currently, little data on the effects of hearing loss on childhood cancer survivors.

We thus undertook a nationwide, populationbased study to examine the impact of hearing loss on HRQoL in children who were recently treated for childhood cancers (1995-2010) and focused on survivors of CNS tumours.

\section{Materials and methods}

\section{Study population}

\section{The Swiss Childhood Cancer Survivor Study (SCCSS)}

The SCCSS is a population-based cohort of all children registered in the Swiss Childhood Cancer Registry (SCCR), who were diagnosed since 1976, survived $\geq 5$ years after initial diagnosis, and were alive at the time of the study [10]. The SCCR includes all patients diagnosed at age $<21$ years in Switzerland with leukaemia, lymphoma, CNS tumours, malignant solid tumours or Langerhans cell histiocytosis [11]. Recent estimates indicate that the SCCR includes $95 \%$ of those diagnosed since 1995 in Switzerland.[12] We included survivors who were 8-15 years old at survey, and diagnosed between 1995-2010. We traced addresses and sent their parents a questionnaire in 2010-2016. Non-responders received a second copy and then were reminded by phone or postal mailing. Ethical approval was granted through the Ethics Committee of the Canton of Bern to the SCCR and the SCCSS (KEK-BE: 166/2014).

\section{Measurements}

\section{SCCSS Questionnaire Survey}

Hearing loss: Parents were asked if a doctor had told them that their child had hearing problems (Supplemental Figure S1). We coded missing answers (4\%) as normal hearing.

HRQoL: We assessed HRQoL with the KIDSCREEN-27 questionnaire for parents [13], which groups 27 items into five dimensions of HRQoL: Physical well-being; psychological well-being; autonomy; parents, peers \& social support; and, school environment. For each item, parents rated their child's HRQoL for the past week on a Likert Scale. For each dimension, we calculated a Rasch score between 0-100 and used international norms to convert them into $\mathrm{T}$ scores (mean $=50 ; \mathrm{SD}=10)$. Higher scores indicate better HRQoL. This instrument has satisfactory psychometric properties [14-16] and has been used in childhood cancer survivors $[5,15]$. We used international norms as Swiss norm data were only available for the Germanspeaking regions [17] and $30 \%$ of our participants were from French- or Italianspeaking regions.

Sociodemographics and chronic health problems: The questionnaire also assessed sociodemographic data and chronic health problems (Supplemental Table S1). For each survivor, we created a sum score of cumulative disease burden by adding the numbers of identified health problems.

\section{SCCR}

Clinical information included age at diagnosis; age at survey; gender; cancer diagnosis; chemotherapy; radiotherapy; brain surgery; bone marrow transplant (BMT); and, relapse during follow-up time. We classified cancer diagnosis according to the International Classification of Childhood Cancer-3rd Edition [18].

\section{Statistical analysis}

We stratified our analyses for tumour types (CNS and non-CNS cancers) since we found previously that survivors of CNS tumour scored low on physical well-being [5], and interaction tests showed that hearing loss had greater effect on the HRQoL dimension peers \& social support in survivors of CNS tumours $\left.\left(\mathrm{p}^{\text {interaction }}=0.005\right]\right)$.

We used t-tests to compare the mean scores of the five KIDSCREEN-27 dimensions of children with hearing loss to those of children with normal hearing and to norm values. We did 
this separately for children with CNS tumours and those with other cancers. Among survivors of CNS tumours, those with hearing loss had worse HRQoL for physical well-being and peers \& social support. For survivors of CNS tumours we then tested if the association might have been confounded by other factors, including sociodemographics, clinical characteristics, cancer treatment, or other chronic health problems (Supplemental Table S2) [19-21]. In multivariable linear regressions, we included a priori age at survey and gender, and all characteristics that had been significantly associated $(\mathrm{p}<0.05)$ with physical well-being and peers \& social support in the univariable models. Likelihood ratio tests determined statistical significance. We performed a sensitivity analysis including those who completed hearing questions $(n=677)$ only and obtained similar results. We used Stata (Version 13, Stata Corporation, Austin, Texas) to calculate Rasch- and T-Scores and to perform all other analysis.

\section{Results}

\section{Characteristics of the study population}

Of 976 parents contacted, 700 returned the questionnaire $(72 \%$ response rate, Supplemental Figure S2). Survivors of CNS tumours $(\mathrm{n}=123)$ were older at diagnosis $(p<0.001)$ and survey $(p=0.003)$, and had more often platinum chemotherapy, cranial radiation, brain surgery, relapses, hearing loss, or more than one health problem (all $\mathrm{p}<0.001$ ) than survivors of other cancers (Tables 1, 2 and 3).

\section{Hearing loss and HRQoL}

In survivors of CNS tumours, hearing loss was associated with poorer physical well-being (with hearing loss: $\mathrm{T}$-score $=44$ vs. normal hearing: $\mathrm{T}$-score $=48, \mathrm{p}=0.047$ ) and peers \& social support (with hearing loss $\mathrm{T}$-score $=40 \mathrm{vs.}$ normal hearing: T-score $=47, \mathrm{p}=0.040$; Figure 1). Differences remained after adjusting for sociodemographic and clinical characteristics and cumulative disease burden (estimated differences: physical well-being [unadjusted 4.6; adjusted -4.0]; peers \& social support [unadjusted -6.7; adjusted -5.0], Supplemental table S2).

In contrast, survivors of other cancers had HRQoL comparable or higher than norm values in all dimensions, and there was no evidence that hearing loss affected HRQoL (all $\mathrm{p}<0.05$, Figure 1).

\section{Discussion}

Survivors of CNS tumours with hearing loss were more likely to feel physically worse and to have poorer relationships to peers than survivors with normal hearing or than the international norm. In survivors of non-CNS cancers hearing loss was not associated with HRQoL.

Our study had both limitations and strengths. Though we based our conclusion on parentreported data [5,22-24,21], validity of selfreported hearing loss was good when compared to information from medical records $[25,26]$. We had no data on hearing aids, though these may affect HRQoL. A strength was the large population-based sample of young, recently diagnosed survivors treated according to the latest treatment protocols, and the comprehensive data available on cancer type, treatment and other chronic health problems.

The only other study that investigated effects of hearing loss on HRQoL in young survivors included 137 US neuroblastoma survivors (nonCNS cancer) [4], and found that survivors with hearing loss were less functional in school, and had lower psychosocial functioning and overall HRQoL. We found no effect of hearing loss in survivors of non-CNS cancers. The US study did not adjust for chronic health problems common in survivors of neuroblastoma, which may have confounded the association [6,7]. A US study in adult survivors $(\mathrm{n}=406)$ reported a negative impact of hearing loss on educational plans and social attainment in both survivors of CNS and non-CNS tumours.[27] It seems that the vulnerability to hearing loss change with increasing age as in our study survivors of CNS tumours only were vulnerable to hearing loss and other survivors could cope better with hearing loss. In our study, survivors of CNS tumours were treated more intensively and their burden of disabilities was higher than in those of non-CNS tumours. This might in return explain the low physical well-being in survivors of CNS tumours, which is consistent with previous studies.[28,5] The HRQoL dimension peers \& social support was particularly affected in survivors of CNS tumours. It might be explained by the fact that they frequently suffer 
from reduced neurocognitive functioning and sometimes have to repeat a year in school.[29]

Since audiological monitoring is only partly implemented for survivors in Switzerland [8], health professionals should pay careful attention to hearing problems and their effects in survivors of CNS tumours. Future studies should investigate if hearing aids or other interventions, including speech therapy, frequency modulation amplification systems or preferential classroom seating, help reducing problems with peers.

\section{Conclusion}

Hearing loss reduces physical well-being and impairs relationships with peers in survivors of CNS tumours, but not in other survivors, so clinicians should be alert to these problems in this vulnerable group. They may benefit most from strict audiological monitoring and timely intervention to mitigate secondary consequences of hearing loss on HRQoL.

\section{Ethical approval}

All procedures performed in studies involving human participants accorded with the ethical standards of the institutional and/or national research committee and with the 1964 Helsinki declaration and its later amendments or comparable ethical standards.

Ethics approval was granted by the Ethics Committee of the Canton of Bern to the SCCR and SCCSS (KEK-BE: 166/2014) and the SCCSS is registered at ClinicalTrials.gov (identifier: NCT03297034).

\section{Informed consent}

Informed consent was obtained from all participants (parents and survivors) for registration in the SCCR and participation in the SCCSS survey.

\section{Conflict of interest}

The authors declare that they have no conflict of interest.

\section{References}

1. Landier, W. (2016). Ototoxicity and cancer therapy. Cancer, 122(11), 1647-1658, doi:10.1002/cncr.29779.

2. Roland, L., Fischer, C., Tran, K., Rachakonda, T., Kallogjeri, D., \& Lieu, J. (2016). Quality of Life in Children with Hearing Impairment: Systematic Review and Meta-analysis. Otolaryngol Head Neck Surg, doi:10.1177/0194599816640485.

3. Lin, C.-Y., \& Fung, X. (2018). The impact of environmental support on health for children with hearing impairment in Taiwan. [Original Article]. Social Health and Behavior, 1(1), 4-10, doi:10.4103/shb.shb_12_18.

4. Gurney, J. G., Tersak, J. M., Ness, K. K., Landier, W., Matthay, K. K., Schmidt, M. L., et al. (2007). Hearing loss, quality of life, and academic problems in long-term neuroblastoma survivors: a report from the Children's Oncology Group. [Comparative Study Research Support, N.I.H., Extramural Research Support, Non-U.S. Gov't]. Pediatrics, 120(5), e1229-1236, doi:10.1542/peds.2007-0178.

5. Wengenroth, L., Gianinazzi, M. E., Rueegg, C. S., Luer, S., Bergstraesser, E., Kuehni, C. E., et al. (2015). Health-related quality of life in young survivors of childhood cancer. Qual Life Res, 24(9), 2151-2161, doi:10.1007/s11136-0150961-3.

6. Laverdiere, C., Cheung, N. K., Kushner, B. H., Kramer, K., Modak, S., LaQuaglia, M. P., et al. (2005). Long-term complications in survivors of advanced stage neuroblastoma. Pediatr Blood Cancer, 45(3), 324-332, doi:10.1002/pbc.20331.

7. Portwine, C., Rae, C., Davis, J., Teira, P., Schechter, T., Lewis, V., et al. (2016). HealthRelated Quality of Life in Survivors of HighRisk Neuroblastoma After Stem Cell Transplant: A National Population-Based Perspective. Pediatr Blood Cancer, 63(9), 1615-1621, doi:10.1002/pbc.26063.

8. Weiss, A., Kuonen, R., Brockmeier, H., Grotzer, M., Candreia, C., Maire, R., et al. (2018). Audiological monitoring in Swiss childhood cancer patients. Pediatr Blood Cancer, 65(3), doi:10.1002/pbc.26877.

9. Children's Oncology Group (2013). Long-Term Follow-Up Guidelines for Survivors of Childhood, Adolescent and Young Adult 
Cancers,

Version

4.0.

www.survivorshipguidelines.org.

10. Kuehni, C. E., Rueegg, C. S., Michel, G., Rebholz, C. E., Strippoli, M. P., Niggli, F. K., et al. (2012). Cohort profile: the Swiss childhood cancer survivor study. [Research Support, NonU.S. Gov't]. Int J Epidemiol, 41(6), 1553-1564, doi:10.1093/ije/dyr142.

11. Michel, G., von der Weid, N. X., Zwahlen, M., Adam, M., Rebholz, C. E., Kuehni, C. E., et al. (2007). The Swiss Childhood Cancer Registry: rationale, organisation and results for the years 2001-2005. [Research Support, Non-U.S. Gov't]. Swiss Med Wkly, 137(35-36), 502-509, doi:2007/35/smw-11875.

12. Schindler, M., Mitter, V., Bergstraesser, E., Gumy-Pause, F., Michel, G., \& Kuehni, C. E. (2015). Death certificate notifications in the Swiss Childhood Cancer Registry: assessing completeness and registration procedures. Swiss Med Wkly, 145, w14225, doi:10.4414/smw.2015.14225.

13. Ravens-Sieberer, U., \& Europe, K. G. (2006). The Kidscreen questionnaires: quality of life questionnaires for children and adolescents; handbook: Pabst Science Publ.

14. Ravens-Sieberer, U., Auquier, P., Erhart, M., Gosch, A., Rajmil, L., Bruil, J., et al. (2007). The KIDSCREEN-27 quality of life measure for children and adolescents: psychometric results from a cross-cultural survey in 13 European countries. Qual Life Res, 16(8), 1347-1356, doi:10.1007/s11136-007-9240-2.

15. Jervaeus, A., Kottorp, A., \& Wettergren, L. (2013). Psychometric properties of KIDSCREEN-27 among childhood cancer survivors and age matched peers: a Rasch analysis. Health Qual Life Outcomes, 11, 96, doi:10.1186/1477-7525-11-96.

16. Jervaeus, A., Lampic, C., Johansson, E., Malmros, J., \& Wettergren, L. (2014). Clinical significance in self-rated HRQoL among survivors after childhood cancer - demonstrated by anchor-based thresholds. Acta Oncol, 53(4), 486-492, doi:10.3109/0284186x.2013.844852.

17. Bisegger, C., Cloetta, B., \& Europe Kidscreen Group (2005). Kidscreen: Fragebogen zur Erfassung der gesundheitsbezogenen Lebensqualität von Kindern und Jugendlichen. Manual der deutschsprachigen Versionen für die Schweiz. Bern: Universität Bern, Abteilung
Gesundheitsforschung des Instituts für Sozialund Präventivmedizin.

18. Steliarova-Foucher, E., Stiller, C., Lacour, B., \& Kaatsch, P. (2005). International Classification of Childhood Cancer, third edition. [Research Support, Non-U.S. Gov't]. Cancer, 103(7), 14571467, doi:10.1002/cncr.20910.

19. Fuemmeler, B. F., Elkin, T. D., \& Mullins, L. L. (2002). Survivors of childhood brain tumors: behavioral, emotional, and social adjustment. Clin Psychol Rev, 22(4), 547-585.

20. Hocking, M. C., McCurdy, M., Turner, E., Kazak, A. E., Noll, R. B., Phillips, P., et al. (2015). Social competence in pediatric brain tumor survivors: application of a model from social neuroscience and developmental psychology. Pediatr Blood Cancer, 62(3), 375384, doi:10.1002/pbc.25300.

21. Schulte, F., Wurz, A., Reynolds, K., Strother, D., \& Dewey, D. (2016). Quality of Life in Survivors of Pediatric Cancer and Their Siblings: The Consensus Between Parent-Proxy and SelfReports. Pediatr Blood Cancer, 63(4), 677-683, doi:10.1002/pbc.25868.

22. van Dijk, J., Huisman, J., Moll, A. C., Schoutenvan Meeteren, A. Y., Bezemer, P. D., Ringens, P. J., et al. (2007). Health-related quality of life of child and adolescent retinoblastoma survivors in the Netherlands. Health Qual Life Outcomes, 5, 65, doi:10.1186/1477-7525-5-65.

23. Matziou, V., Perdikaris, P., Feloni, D., Moschovi, M., Tsoumakas, K., \& Merkouris, A. (2008). Cancer in childhood: children's and parents' aspects for quality of life. Eur J Oncol Nurs, 12(3), 209-216, doi:10.1016/j.ejon.2007.10.005.

24. Laffond, C., Dellatolas, G., Alapetite, C., Puget, S., Grill, J., Habrand, J. L., et al. (2012). Qualityof-life, mood and executive functioning after childhood craniopharyngioma treated with surgery and proton beam therapy. Brain Inj, 26(3),

270-281, doi:10.3109/02699052.2011.648709.

25. Weiss, A., Sommer, G., Kuonen, R., Scheinemann, K., Grotzer, M., Kompis, M., et al. (2017). Validation of questionnaire-reported hearing with medical records: A report from the Swiss Childhood Cancer Survivor Study. PLoS One, 12(3), e0174479, doi:10.1371/journal.pone.0174479. 
26. Louie, A. D., Robison, L. L., Bogue, M., Hyde, S., Forman, S. J., \& Bhatia, S. (2000). Validation of self-reported complications by bone marrow transplantation survivors. Bone Marrow Transplant, 25(11), 1191-1196, doi:10.1038/sj.bmt. 1702419.

27. Brinkman, T. M., Bass, J. K., Li, Z., Ness, K. K., Gajjar, A., Pappo, A. S., et al. (2015). Treatmentinduced hearing loss and adult social outcomes in survivors of childhood CNS and non-CNS solid tumors: Results from the St. Jude Lifetime Cohort Study. Cancer, 121(22), 4053-4061, doi:10.1002/cncr.29604.
28. Engelen, V., Koopman, H. M., Detmar, S. B., Raat, H., van de Wetering, M. D., Brons, P., et al. (2011). Health-related quality of life after completion of successful treatment for childhood cancer. Pediatr Blood Cancer, 56(4), 646-653, doi:10.1002/pbc.22795.

29. Barrera, M., Shaw, A. K., Speechley, K. N., Maunsell, E., \& Pogany, L. (2005). Educational and social late effects of childhood cancer and related clinical, personal, and familial characteristics. Cancer, 104(8), 1751-1760, doi:10.1002/cncr.21390. 
Table 1 Sociodemographic characteristics of the study population

\begin{tabular}{|c|c|c|c|}
\hline & \multicolumn{3}{|c|}{ Study participants } \\
\hline & \multirow{2}{*}{$\begin{array}{c}\begin{array}{c}\text { CNS tumours } \\
n=123\end{array} \\
\text { mean (SD) }\end{array}$} & \multicolumn{2}{|c|}{$\begin{array}{c}\begin{array}{c}\text { Non-CNS cancers } \\
\mathbf{n}=\mathbf{5 7 7}\end{array}\end{array}$} \\
\hline & & mean (SD) & p-value $^{a}$ \\
\hline Age at survey, years & $13(2)$ & $12(2)$ & 0.003 \\
\hline Sociodemographic characteristics & $\mathrm{n}\left(\%^{\mathrm{b}}\right)$ & $\mathrm{n}\left(\%^{\mathrm{b}}\right)$ & p-value ${ }^{c}$ \\
\hline Gender & & & 0.100 \\
\hline Female & $62(50)$ & $244(42)$ & \\
\hline Migration background $^{\mathrm{d}}$ & & & 0.568 \\
\hline No & $92(75)$ & $417(72)$ & \\
\hline Yes & $31(25)$ & $160(28)$ & \\
\hline Language region of Switzerland & & & 0.612 \\
\hline German speaking & $90(73)$ & $400(69)$ & \\
\hline French speaking & $29(24)$ & $149(26)$ & \\
\hline Italian speaking & $4(3)$ & $28(5)$ & \\
\hline Parental education ${ }^{\mathrm{e}, \mathrm{f}}$ & & & 0.704 \\
\hline Primary & $8(7)$ & $50(9)$ & \\
\hline Secondary & $77(63)$ & $346(60)$ & \\
\hline Tertiary & $34(28)$ & $163(28)$ & \\
\hline Child lives with/in & & & 0.784 \\
\hline Both parents & $103(84)$ & $464(80)$ & \\
\hline One parent and partner & $7(6)$ & $38(7)$ & \\
\hline One parent & $12(10)$ & $67(12)$ & \\
\hline Institution & $1(1)$ & $2(1)$ & \\
\hline Siblings & & & 0.237 \\
\hline No sibling & $12(10)$ & $79(15)$ & \\
\hline Has sibling(s) & $109(90)$ & $488(85)$ & \\
\hline
\end{tabular}

Abbreviations: CNS, central nervous system, n, number; SD, standard deviation.

${ }^{\text {ap}} \mathrm{P}$-values calculated from t-tests comparing survivors of CNS to survivors of non-CNS tumours.

${ }^{\mathrm{b}}$ Column percentages are given.

${ }^{\mathrm{c}} \mathrm{P}$-values calculated from chi-square tests comparing survivors of CNS to survivors of nonCNS tumours.

${ }^{\mathrm{d}}$ We classified participants who were not Swiss citizens at birth, not born in Switzerland, or had at least one parent who was not a Swiss citizen as having a migration background.

${ }^{\mathrm{e}} \mathrm{We}$ classified parental education into three categories: primary education (compulsory schooling only [ $\leq 9$ years]), secondary education (vocational training [10-13 years]), and tertiary education (higher vocational training, college, or university degree). If parents achieved different levels of education, we selected the parent with the highest education. ${ }^{\mathrm{f}}$ Numbers and percentages are based upon available data. 
Table 2 Clinical characteristics of the study population

\begin{tabular}{|c|c|c|c|}
\hline & \multicolumn{3}{|c|}{ Study participants } \\
\hline & \multirow{2}{*}{$\begin{array}{c}\begin{array}{c}\text { CNS tumours } \\
n=123\end{array} \\
\text { mean (SD) } \\
\end{array}$} & \multicolumn{2}{|c|}{ 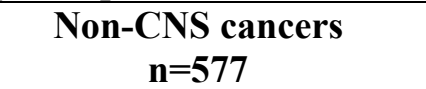 } \\
\hline & & mean (SD) & p-value ${ }^{a}$ \\
\hline Age at diagnosis, years & $5(3)$ & $3(2)$ & $<0.001$ \\
\hline Sociodemographic characteristics & $\mathrm{n}\left(\%^{\mathrm{b}}\right)$ & $\mathrm{n}\left(\%^{\mathrm{b}}\right)$ & p-value $e^{c}$ \\
\hline \multicolumn{4}{|l|}{ Clinical characteristics } \\
\hline Diagnosis (ICCC-3) & & & n.a. \\
\hline I Leukaemias & - & $273(47)$ & \\
\hline II Lymphomas & - & $50(9)$ & \\
\hline III CNS tumours & $123(100)$ & $0(0)$ & \\
\hline IV Neuroblastoma & - & $61(11)$ & \\
\hline V Retinoblastoma & - & $38(7)$ & \\
\hline VI Renal tumours & - & $51(9)$ & \\
\hline VII Hepatic tumours & - & $12(2)$ & \\
\hline VIII Bone tumours & - & $12(2)$ & \\
\hline IX Soft tissue sarcomas & - & $46(8)$ & \\
\hline X Germ cell tumours & - & $11(2)$ & \\
\hline XI \&XII Other rare tumours ${ }^{\mathrm{d}}$ & - & $2(1)$ & \\
\hline Langerhans cell histiocytosis & - & $21(4)$ & \\
\hline \multicolumn{4}{|l|}{ Treatments } \\
\hline Chemotherapy & & & $<0.001$ \\
\hline Platinum & $43(35)$ & $107(19)$ & \\
\hline No platinum & $8(7)$ & $415(72)$ & \\
\hline Unknown platinum use & $2(2)$ & $1(1)$ & \\
\hline No chemotherapy & $70(57)$ & $54(9)$ & \\
\hline Cranial radiotherapy & & & $<0.001$ \\
\hline Yes, Gray ${ }^{\mathrm{e}}$ & $32(26)$ & $46(8)$ & \\
\hline $1-29$ & $3(9)$ & $30(65)$ & \\
\hline$\geq 30$ & $27(84)$ & $13(28)$ & \\
\hline No & $91(74)$ & $531(92)$ & \\
\hline Surgery & & & $<0.001$ \\
\hline Brain surgery & $72(59)$ & $14(2)$ & \\
\hline CSF-shunt & $6(5)$ & $0(0)$ & \\
\hline Both & $26(21)$ & $0(0)$ & \\
\hline Bone marrow transplantation ${ }^{\mathrm{e}}$ & & & 0.044 \\
\hline No & $116(97)$ & $521(92)$ & \\
\hline Yes & $3(3)$ & $43(8)$ & \\
\hline Relapse & & & $<0.001$ \\
\hline No & $86(70)$ & $525(91)$ & \\
\hline Yes & $37(30)$ & $52(9)$ & \\
\hline
\end{tabular}

Abbreviations: CNS, central nervous system, ICCC-3, International Classification of childhood cancer n, number; SD, standard deviation.

${ }^{\text {aP}} \mathrm{P}$-values calculated from t-tests comparing survivors of CNS to survivors of non-CNS tumours.

${ }^{\mathrm{b} C o l u m n}$ percentages are given.

${ }^{\mathrm{c} P}$-values calculated from chi-square tests comparing survivors of CNS to survivors of nonCNS tumours.

${ }^{\mathrm{d}}$ Other malignant epithelial neoplasms, malignant melanomas and other unspecified malignant neoplasms.

${ }^{\mathrm{e}}$ Numbers and percentages are based upon available data. 
Table 3 Health outcomes of the study population

\begin{tabular}{|c|c|c|c|}
\hline & \multicolumn{3}{|c|}{ Study participants } \\
\hline & \multirow{2}{*}{$\begin{array}{c}\begin{array}{c}\text { CNS tumours } \\
n=123\end{array} \\
\begin{array}{c}n \\
\left(\% \%^{a}\right)\end{array}\end{array}$} & \multicolumn{2}{|c|}{ 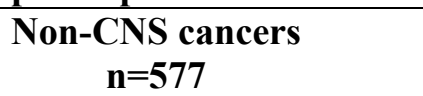 } \\
\hline & & n $\left(\%^{a}\right)$ & p-value ${ }^{b}$ \\
\hline Hearing outcomes & & & $<0.001$ \\
\hline Normal hearing & $98(80)$ & $533(92)$ & \\
\hline Hearing loss & $25(20)$ & $44(8)$ & \\
\hline Severity of hearing loss & & & 0.471 \\
\hline Mild & $13(52)$ & $25(57)$ & \\
\hline Moderate & $8(32)$ & $9(20)$ & \\
\hline Severe (deaf) & $3(12)$ & $4(9)$ & \\
\hline Unknown & $1(4)$ & $6(13)$ & \\
\hline Laterality of hearing loss & & & 0.490 \\
\hline Unilateral & $6(24)$ & $13(30)$ & \\
\hline Bilateral & $17(68)$ & $24(55)$ & \\
\hline Unknown & $2(8)$ & $7(16)$ & \\
\hline \multicolumn{2}{|c|}{ Chronic health problems/Cumulative disease burden } & & $<0.001$ \\
\hline 0 & $32(26)$ & $331(57)$ & \\
\hline 1 & $30(24)$ & $141(24)$ & \\
\hline 2 & $28(23)$ & $70(12)$ & \\
\hline 3 or more & $33(27)$ & $35(6)$ & \\
\hline
\end{tabular}

Abbreviations: CNS, central nervous system, $n$, number.

${ }^{a}$ Column percentages are given.

${ }^{\mathrm{b}} \mathrm{P}$-values calculated from chi-square tests comparing survivors of CNS to survivors of nonCNS tumours. 
Fig. 1 Mean scores from KIDSCREEN-27 comparing survivors with hearing loss and normal hearing stratified by tumour type.

Higher scores indicate better HRQoL. International norms have a sore of $50 \pm 10$ (SD). P-values calculated from t-tests comparing survivors with hearing loss and normal hearing.

Abbreviations: CI, confidence interval; CNS, central nervous system; $p$, p-value.




Title: Hearing loss and quality of life in survivors of paediatric CNS tumours and other cancers,

\section{Quality of Life Research}

Annette Weiss, Grit Sommer, Christina Schindera, Laura Wengenroth, Axel Karow, Manuel Diezi, Gisela Michel, Claudia E. Kuehni1 ${ }^{1,2}$, for the Swiss Paediatric Oncology Group (SPOG)

${ }^{1}$ Swiss Childhood Cancer Registry, Institute of Social and Preventive Medicine, University of Bern,

Finkenhubelweg 11, 3012 Bern, Switzerland.

2Division of Pediatric Hematology/Oncology, Department of Pediatrics, Inselspital, Bern University Hospital, University of Bern, Freiburgerstrasse 15, 3010 Bern, Switzerland.

E-mail: claudia.kuehni@ispm.unibe.ch

Have you been told by a doctor that your child have, or have had ...

No Yes $\begin{gathered}\text { If yes, when was it } \\ \text { diagnosed the first } \\ \text { time? } \\ \text { Before }\end{gathered}$

Problems with hearing

If yes, which problems?

Mild problems, not requiring hearing aids or completely corrected with hearing aid

Moderate problems, not completely corrected by hearing aid

Severe problems, not correctable by hearing aid (deaf)

Are one or both ears affected?

$\square$ One ear $\square$ Both ears

Supplementary Figure S1 Questions on hearing from the Swiss Childhood Cancer Survivors Study Questionnaire 


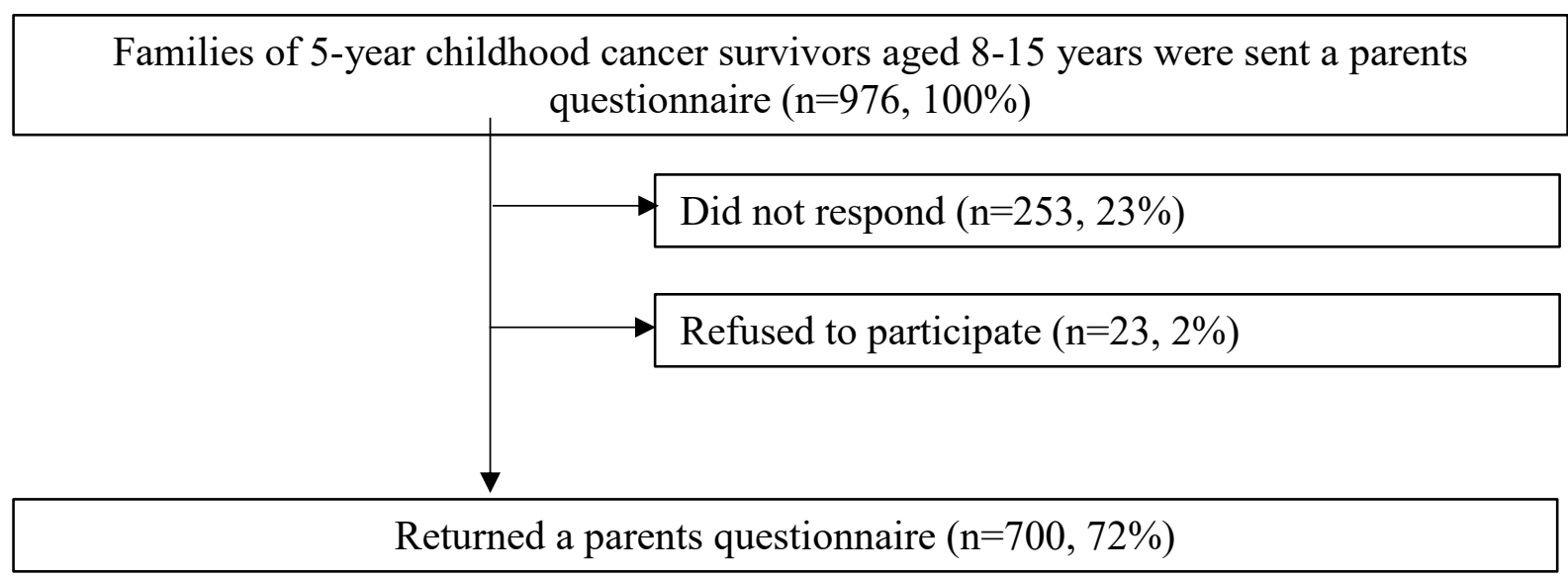

Supplementary Figure S2 Response rate among parents of childhood cancer survivors in the Swiss Childhood Cancer Survivor Study 
Supplementary Table S1 Classification of chronic health problems

\begin{tabular}{lll}
\hline Chronic health problems $^{\mathrm{a}}$ & Symptoms/disease within each problem & $\mathrm{n}$ \\
\hline Visual impairment $\mathrm{n}=123$ & - Eye motility dysfunction & 23 \\
& - Moderate to severe visual impairment or blindness & 64 \\
& - in one or both eyes & 17 \\
& - Slaucoma & 57 \\
\hline Speech difficulty $\mathrm{n}=58$ & - Strabismus & 58 \\
\hline Cardiac problem $\mathrm{n}=32$ & - Cardiac arrhythmia & 14 \\
& - Cardiac insufficiency & 3 \\
& - Deep vein thrombosis or lung embolism & 4 \\
& - Heart valve disease & 11 \\
\hline Pulmonary problem $\mathrm{n}=20$ & - Stroke & 6 \\
\hline Endocrine problem $\mathrm{n}=78$ & - Moderate or severe asthma & 20 \\
& - Recurrent pneumonia & 14 \\
\hline Neurological problems $\mathrm{n}=144$ & - Diabetes & 15 \\
& - Hypo- or hyperthyroidism & 49 \\
& - Growth hormone deficiency & 61 \\
\hline Musculoskeletal problems $\mathrm{n}=152$ & - Reduced sensitivity of the arms or legs & 56 \\
& - Balance disorders & 66 \\
& - Reduced range of motion of joints & 99 \\
\hline
\end{tabular}

a Survivors were classified as having had the respective chronic health problem if they reported at least one of the specific symptoms.

Missing information for visual impairment $7 \%$, musculoskeletal problem $2 \%$, neurological problem $1 \%$, speech difficulty $1 \%$, cardiac problem $2 \%$, pulmonary problem $1 \%$, and endocrine problem $1 \%$. 


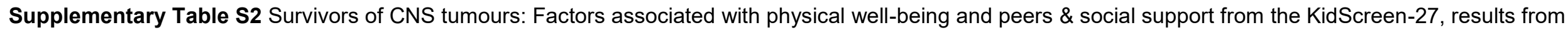
linear regression

\begin{tabular}{|c|c|c|c|c|c|c|c|c|}
\hline & \multicolumn{4}{|c|}{ Physical well-being } & \multicolumn{4}{|c|}{ Peers \& social support } \\
\hline & \multicolumn{2}{|c|}{ Univariable models } & \multicolumn{2}{|c|}{ Multivariable model $^{b}$} & \multicolumn{2}{|c|}{ Univariable models } & \multicolumn{2}{|c|}{ Multivariable modelc } \\
\hline & Coef $(95 \% \mathrm{Cl})$ & $\mathrm{Pa}$ & Coef $(95 \% \mathrm{Cl})$ & $\mathrm{Pa}$ & Coef $(95 \% \mathrm{Cl})$ & $\mathrm{Pa}$ & Coef $(95 \% \mathrm{Cl})$ & $\mathrm{Pa}$ \\
\hline Hearing loss & & 0.047 & & 0.026 & & 0.040 & & 0.091 \\
\hline No & Ref & & Ref & & Ref & & Ref & \\
\hline Yes & $-4.6(-9.2 ;-0.1)$ & & $-4.0(-7.6 ;-0.3)$ & & $-6.7(-13.0 ;-0.3)$ & & $-5.0(-10.9 ; 0.9)$ & \\
\hline \multicolumn{9}{|l|}{ Sociodemographics } \\
\hline Age at survey per 5 years & $-1.6(-5.7 ; 2.6)$ & 0.453 & $-3.9(-7.2 ;-0.6)$ & 0.015 & $5.0(1.4 ; 8.6)$ & 0.006 & $1.5(-3.6 ; 6.6)$ & 0.535 \\
\hline Gender & & 0.394 & & 0.686 & & 0.053 & & 0.008 \\
\hline Male & Ref & & Ref & & Ref & & Ref & \\
\hline Female & $-1.6(-5.2 ; 2.1)$ & & $-0.6(-3.4 ; 2.3)$ & & $4.8(-0.1 ; 9.7)$ & & $6.0(1.4 ; 10.5)$ & \\
\hline Migration background & & 0.516 & & & & 0.399 & & \\
\hline No & Ref & & & & Ref & & & \\
\hline Yes & $-1.4(-5.6 ; 2.8)$ & & & & $2.5(-3.3 ; 8.2)$ & & & \\
\hline Language region & & 0.035 & & 0.012 & & 0.325 & & \\
\hline German & Ref & & Ref & & Ref & & & \\
\hline French & $-2.9(-7.0 ; 1.4)$ & & $-3.3(-6.6 ; 0.1)$ & & $-2.2(-8.0 ; 3.6)$ & & & \\
\hline Italian & $-11.9(-21.9 ;-1.9)$ & & $-9.5(-17.5 ;-1.4)$ & & $-9.4(-23.2 ; 4.3)$ & & & \\
\hline Parental education & & 0.252 & & & & 0.403 & & \\
\hline Primary & Ref & & & & Ref & & & \\
\hline Secondary & $2.2(-5.2 ; 9.7)$ & & & & $2.7(-7.3 ; 12.7)$ & & & \\
\hline Tertiary & $5.2(-2.7,13.0)$ & & & & $5.9(.4 .7 ; 16.5)$ & & & \\
\hline Having siblings & & 0.619 & & & & 0.207 & & \\
\hline No & Ref & & & & Ref & & & \\
\hline Yes & $-1.7(-8.3 ; 5.0)$ & & & & $-5.7(-14.6 ; 3.2)$ & & & \\
\hline \multicolumn{9}{|l|}{$\begin{array}{l}\text { Cumulative disease } \\
\text { burden }\end{array}$} \\
\hline $\begin{array}{l}\text { Number of additional } \\
\text { health problems }\end{array}$ & & $<0.001$ & & $<0.001$ & & $<0.001$ & & $<0.001$ \\
\hline 0 & Ref & & Ref & & Ref & & Ref & \\
\hline 1 & $-5.4(-9.6 ;-1.2)$ & & $-5.8(-9.8 ;-1.7)$ & & $-7.3(-13.6 ;-0.9)$ & & $-6.9(-13.2 ;-0.7)$ & \\
\hline 2 & $-9.8(-14.1 ;-5.5)$ & & $-9.0(-13.2 ;-4.8)$ & & $-9.9(-16.4 ;-3.4)$ & & $-10.7(-17.2 ;-4.2)$ & \\
\hline 3 or more & $-15.1(-19.3 ;-10.9)$ & & $-14.7(-18.7 ;-10.8)$ & & $-15.5(-21.8 ;-9.2)$ & & $-14.9(-21.1 ;-8.7)$ & \\
\hline \multicolumn{9}{|l|}{ Clinical factor } \\
\hline $\begin{array}{l}\text { Age at diagnosis per } \\
\text { 5years }\end{array}$ & $-0.4(-1.1 ; 0.3)$ & 0.284 & & & $0.8(-0.1 ; 1.8)$ & 0.090 & & \\
\hline Having relapse & & 0.001 & & 0.005 & & 0.267 & & \\
\hline No & Ref & & Ref & & Ref & & & \\
\hline Yes & $-6.3(-10.1 ;-2.5)$ & & $-4.4(-7.6 ;-1.2)$ & & $-3.0(-8.5 ; 2.4)$ & & & \\
\hline
\end{tabular}

Abbreviations: CNS, central nervous system; coef, coefficient; Ref, reference; $\mathrm{Cl}$, confidence interval. 
aP-values derived from likelihood ratio tests

${ }^{\mathrm{b}}$ Adjusted for gender, age at survey, language region, cumulative disease burden, and having had a relapse.

${ }^{\mathrm{c} A d j u s t e d}$ for gender, age at survey, cumulative disease burden.

Selection of confounders: We tested age at diagnosis, cumulative disease burden, language region, migration background, parental education, having siblings and having had a relapse in univariable linear regression analysis. In multivariable regression models we included a priori gender and age at survey and confounders with $p<0.05$ in univariable regressions. 